\title{
InDEX OF ADVERTISERS
}

4pi Analysis, Inc (www.4pi.com)

Advanced Microscopy Techniques(www.amtimaging.com)...

CamScan USA (www.camscan-usa.com) .

Digilab USA (www.digilabglobal.com).

EBSciences (ebs@ebsciences.com).

EDAX Inc.(www.edax.com)

EMPIX Imaging (www.empix.com)

Ernest F. Fullam (www.fullam.com)

FEI Company (www.feic.com)

Gatan Inc. (www.gatan.com)

Geller MicroAnalytical Lab (www.gellermicro.com)

Hitachi High Technologies America (www.hitachi-hhta.com)...

IXRF Systems (www.ixrfsystems.com)

JEOL USA (www.jeol.com)

LabX (www.labx.com).

LEO Electron Microscopy (www.leo-usa.com).

M.E. Taylor Engineering (www.semsupplies.com)
25 Materials Analytical Services (MAS) (www.mastest.com)

\section{7}

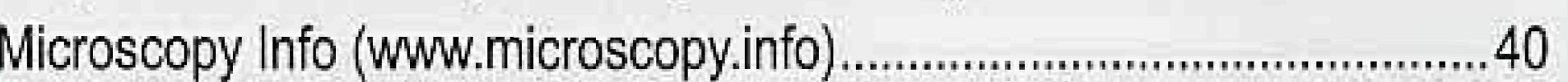

Micro Star Technologies (www. Microstartech.com) .........................43

National Graphic Supply (www.ngscorp.com) ...................................12

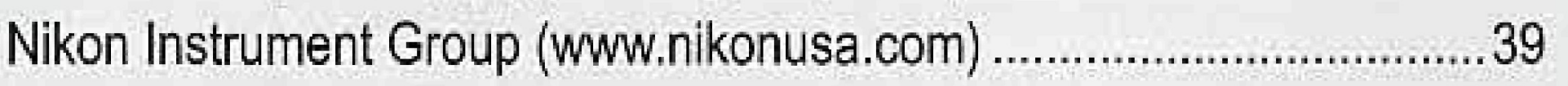

Princeton Gamma Tech (www.pgt.com) ..........................................

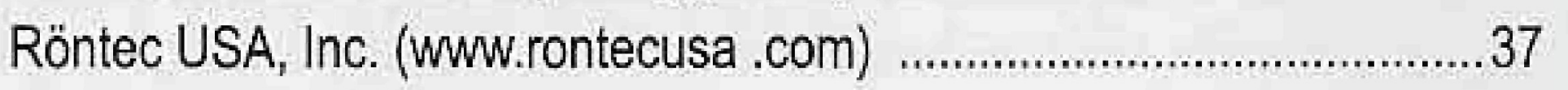

ScopeTronix Quality Products (www.scopetronix.com) ........................37

SensIR Technologies (www.sensir.com/objective) ........................14, 15

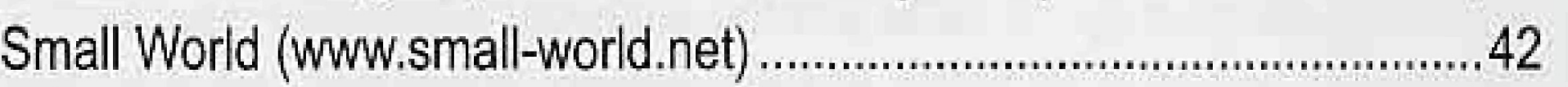

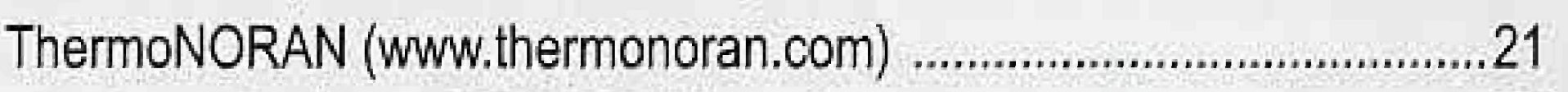

XEI Scientific (www.SEMCLEAN.com) ............................................. 33

Employment Advertisements

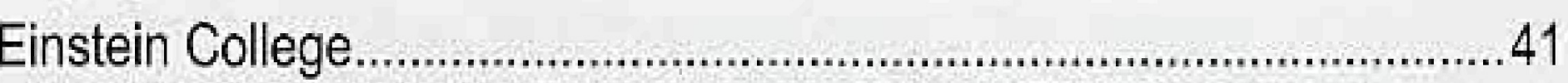

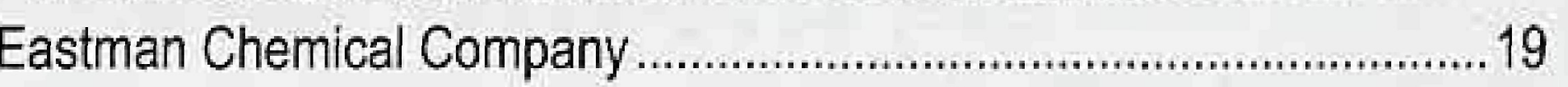

\section{SUBSORIPTIOA REQUESTS/OHANGES}

\section{Individuals requesting subscriptions, or wishing to change/correct their current address, are requested to do so via our www site:}

http://www.microscopy-today.com

Microscopy Today has new subscription policies: First: We have redefined the "free to US" rule by adding microscopists in Canada and Mexico to the free eligibility list. Second: We have scanned back issues of MT into computer files, which we now make available for free download anywhere in the world after a six-month delay. The entire issues are downloaded-advertisements and all. Non-North American MSA members may download the current issue with a password provided on request. The magazine was scanned and saved as high-resolution JPEG files that are about 30MB per issue. Very few individuals can download files that large, so we created a second set of PDFs that are about 9MB per issue for downloading purposes. The PDFs are called "low resolution" products in the table below. The 2002 issues are available now at http://www.microscopy-today.com. The most recent five years are scanned and will probably be available for downloading soon. We will scan-in and make available the remaining issues back to 1992 shortly.

We have lowered our subscription rate for the printed magazine from $\$ 80-\$ 110$ to $\$ 35 \mathrm{US}$ per year-a sum that just covers postage and handling! MSA members outside North America wishing to have printed copies after 2003 will have to subscribe at $\$ 35 U S$.

The high resolution CD format issues are also available via airmail for $\$ 20$ US per issue (\$15US/issue for MSA members). Entire volumes in high resolution JPEG format are available at $\$ 100$ US/volume for individuals or $\$ 180$ US/volume for libraries and institutions. Note that a volume contains 6 issue for 2002 onwards and 10 issues for 1992 to 2001 . Preferred payment is via credit card information when subscribing at the same www address. Bank transfer information available from editor. Checks in US\$, payable to "Microscopy Today," to the editor.

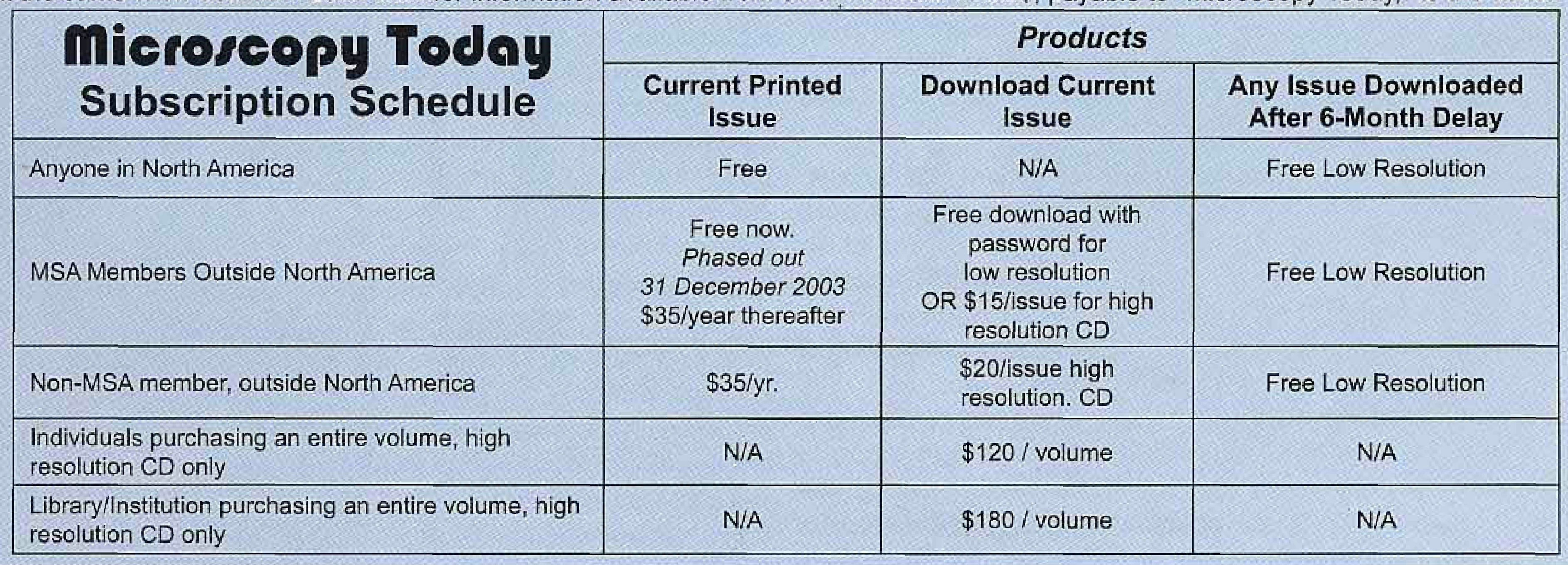

